\title{
Optimal bond issuance with cost and liquidity constraints for Chinese local governments: a multi-period stochastic programming approach
}

\author{
Ruicheng Yang ${ }^{1} \cdot \mathrm{Li} \mathrm{Li}^{2} \mathbb{C} \cdot \mathrm{Qi}$ Jiang $^{1} \cdot \mathrm{Ji}^{\mathrm{Q} \mathrm{i}^{1}}$
}

Received: 5 March 2021 / Accepted: 20 January 2022 / Published online: 9 February 2022

(c) The Author(s), under exclusive licence to Springer-Verlag GmbH Germany, part of Springer Nature 2022

\begin{abstract}
In recent years, China's local governments have issued numerous bonds to support the country's economic development. However, as total debt accumulates, the pressure on debt repayments is gradually increasing. To increase the sustainability of local government debt, we propose a multi-period stochastic optimization-based approach to determining the portfolio composition of issued bonds, with the goal of minimizing the expected cost under the constraints of liquidity risk and cost deviation risk. Liquidity risk is measured by conditional payment-at-risk $(C P a R)$, and cost deviation risk is measured by conditional value-at-risk $(C V a R)$. By bounding $C V a R$ and $C P a R$, local governments can control the levels of cost deviation risk and liquidity risk. To alleviate future liquidity risk, which is caused by the issuance of a large number of long-term bonds to deliberately reduce repayment pressure within a debt planning horizon, we consider an extended liquidity planning horizon to manage both current and future liquidity risk. Based on this, we analyze the efficient frontier and portfolio compositions of issued bond under the constraints of different $C V a R$ and $C P a R$ levels. Compared with actual Chinese local government bond portfolios, the efficient frontier performs better for different issuance strategies.
\end{abstract}

\footnotetext{
$\mathrm{Li} \mathrm{Li}$

lyanlin2010@gmail.com

Ruicheng Yang

yang-ruicheng@163.com

Qi Jiang

jiangqi0410@126.com

Ji Qi

aclekenn@gmail.com

1 School of Finance, Inner Mongolia University of Finance and Economics, Hohhot, China

2 School of Management, Marist College, Poughkeepsie, NY 12601, USA
} 
Keywords Local government bonds $\cdot$ Bond cost $\cdot$ Liquidity risk $\cdot$ Stochastic programming

\section{Introduction}

China's local government debt has grown rapidly over the last few decades. The debt has been issued mainly to meet the funding requirements arised from excess payments, interest on outstanding debt, refinancing maturing debt and support for infrastructure development (Ferrarini et al. 2012; Eisl et al. 2016). Following the outbreak of COVID-19 pandemic, many provinces in China, such as Jiangsu and Henan, also issued bonds to stimulate economic growth. However, with the accumulation of total debt, the sustainability of local government debt has drawn increasing attention from the authorities. Sound debt management at the local government level plays an important role in enabling the government to meet its obligations, and it is also a key determinant factor of the fiscal and economic sustainability of local governments (Draksaite et al. 2015). In particular, as downward pressure on China's economy increases, it is necessary to find an effective local government bond issuance strategy to maintain debt sustainability and economic growth. On the other hand, the current research on the local government debt in China focuses on the investigation of its debt risks (see, e.g., Wang and Fan (2012), Fang and Chai (2017), Yin and Chen (2018), Sun (2019), Shi et al. (2020), Hu et al. (2020), Tang et al. (2020)), and the research on debt issuance strategy is relatively rare. Therefore, it is also necessary to find a sound local government debt issuing strategy from both practical and theoretical perspectives.

At present, in China, but not limited to China, local government bond issuance largely exists in the situation of borrowing new debt to repay old bonds. Specifically, an important task to issue long-term bonds for some local governments is to repay their debts in the current stage. This leads that the average debt maturity gradually increases, which means the proportion of long-term bonds is increasing accordingly. From the perspective of debt management, issuing long-term bonds to repay debts in the current stage is equivalent to transferring current debts to the future. This approach can indeed mitigate short-term debt repayment pressure and debt risks, but it is also equivalent to transferring short-term debt risks to the future. Especially for regions with high debt to GDP ratio (see, e.g., Ferrari (2018), Missale (2000)), more and more long-term bonds are issued in order to repay debts in the current stage, which lays great hidden troubles for future debt management. In this paper, we are not to against issuing long-term debt, because issuing long-term debt does mitigate the debt risk in the current stage. Thus, how to control the future debt risk becomes a priority when issuing long-term bonds, this can be accomplished through managing the cash flow of payments caused by long-term debt in the future, and it is beneficial to improving debt sustainability. In addition, another important debt risk is target deviation risk. Here, the deviation is the difference between the optimal debt issuing strategy and the actual debt issuing strategy. In other words, the larger the deviation is, the more the debt issuing strategy deviates from the policy makers' debt management target involved with the optimal debt issuing strategy. 
Following previous studies (Adamo et al. (2004), Hahm and Kim, (2003), Bolder (2003), Date et al. (2011), Proite (2015), Eisl et al. (2016), Zenios et al. (2019), Ferrari (2018), Bhandari et al. (2017)), we consider debt issuance strategies in terms of the cost and risk of government debt. In this paper, we aim at minimizing the expected cost of local government debt and seeking the optimal local government bond issuance strategy on the basis of controlling current and future liquidity risks and target deviation risks of debt. Specifically, for the liquidity risk, we consider the debt cash flow payments as two parts of local governments, namely, the cash flow within the liquidity management term (short-term liquidity risk) and the cash flow paid within the extended liquidity management term (long-term liquidity risk). By managing these two kinds of cash flows, we manage the current and future liquidity risk of local government debt simultaneously. On the other hand, when the cost of local government debt is taken as target, the target deviation risk of local government debt is the deviation level between the cost of its debt issuing strategy and the expected cost of debt. Therefore, we also constrain the deviation level to control the risk of target deviation. On this basis, we use the multi-period stochastic programming model to analyze the effective boundary of local government debt management and constrain its different risk levels.

The main contributions of this paper can be summarized as follows. Firstly, due to the fact that local governments repay short-term bonds by issuing long-term bonds, we control both current and future liquidity risk in the bond issuance process. Managing this future debt risk can help local governments to improve the sustainability of debt management. Secondly, the constraints of liquidity risk and target deviation risk are both introduced into the multi-period stochastic programming model. Thirdly, by analyzing the empirical results, we find that under a fixed constraint of liquidity risk (CPaR), decision-makers can select different levels of expected cost by converting each proportion of those bonds matured after the extending liquidity risk horizon. In addition, under a fixed constraint of cost deviation risk (CVaR), decision-makers can select different repayment levels by converting the total proportions of those two types of bonds, which matures before or after the extending liquidity risk horizon, to alleviate current or future liquidity risk.

The rest of this paper is organized as follows. Section 2 describes the background and features of the local government debt problem. Section 3 presents our multi-period stochastic programming model. Section 4 shows how we use our model to analyze the efficient frontier and bond portfolio compositions under different risk constraints associated with the issuance of Chinese local government bonds. Section 5 details the main contributions of this paper and outlines directions for future research.

\section{The problem of local government debt management}

Local governments issue debt for two main reasons: (1) to meet their net cash requirements for fiscal running and operations and (2) to repay their maturing bonds (Balibek and Köksalan 2010; Consiglio and Staino 2012). When issuing debt to meet their funding requirements, local governments face complex economic or fiscal circumstances, 
so the objectives of bond issuance may vary. Local governments must overcome obstacles to debt management due to various complex factors (1) The frequent issuance of government bonds increases the uncertainty of bond prices in the domestic bond market (Faraglia et al. 2019). (2) The central government may have specific requirements for the bond issuance portfolios of local governments to develop the domestic secondary bond market, which plays a significant role in the central bank's monetary policy. (3) As important participants in the domestic bond market, local governments can adopt convenient means to achieve their desired aims, such as by decreasing the issuance interest rate to reduce the bond cost, but this may induce fluctuation in the domestic bond market. (4) Financial assistance from the central government also affects the debt management strategies of local governments. Due to the complexity of these circumstances, it is very difficult for local governments to find a perfect issuance strategy to solve all of the problems caused by these factors at the same time.

A common aim of most local governments and researchers is to minimize the expected cost of issued bonds under different risk constraints. Similar to the Markowitz's portfolio management theory (Markowitz 1952), the trade-off between cost and different types of risk, such as liquidity risk and cost deviation risk, is a traditional challenge for decision-making on local government bond issuance. In this paper, we focus on liquidity risk and cost deviation risk with respect to minimizing the expected cost for issuance strategies.

In the real world, when local governments with poor fiscal status are required to repay a large amount of maturing debt, controlling liquidity risk is particular important. Liquidity risk control strategies need to consider the debt repayment levels of local governments at each issuance stage. In particular, when local government debt accumulation becomes very serious, to reduce repayment pressure, decision-makers can often maintain a good cash flow only by issuing long-term bonds, thereby alleviating the short-term payment pressure of outstanding debts. However, transferring current repayment pressure and liquidity risk to the future, which may also face greater payment pressure and liquidity risk in the future. Existing liquidity risk management strategies for local governments usually concentrate on current risk, to some extent underestimating future liquidity risk. This may trigger a significant liquidity crisis in the future. Cost deviation risk is another critical form of risk for local governments to consider when developing debt management strategies. This type of risk represents the distance between debt cost and the desired target of decision-makers for bond issuance. Generally, local governments have different objectives due to the complex variation in their circumstances. The deviation between debt cost and the desired target reflects the preference of local governments for different bond issuance strategies. In many cases, there is a trade-off between debt cost and cost deviation risk, as reducing the cost deviation risk may incur a higher debt cost. Local governments can choose different debt costs associated with different issuance strategies by considering their tolerance of cost deviation risk.

In addition, to control the debt risk of local governments, the Chinese central government has also introduced some restrictions to manage local government debt as follows: First, the central government sets a debt ceiling for each local government according to its economic development and debt level, that is, the total amount of bonds issued by local governments cannot exceed the debt ceiling. Second, although 
the central government allows local governments to alleviate the current repayment pressure by borrowing new debt to repay old ones, the central government has also limited the size of new bond issued to repay old debts. Third, the central government will not bail out local governments in the event of a debt crisis. Local governments, for their part, have taken sound measures to mitigate debt risks from the following four aspects: i) improving the local government debt management system; ii) ensuring that the growth rate of local government debt does not exceed the annual GDP growth rate of the region; iii) repaying local government debts on time, reducing debt repayment pressure, and maintaining financial health; iv) establishing a risk warning mechanism for its debt management.

Given the above considerations, in this paper, we focus on bond issuance portfolio composition with the goal of minimizing debt cost under risk constraints. We aim to answer the following questions. (1) How can we control future repayment cash flow and liquidity risk after the debt planning horizon? (2) Given the bond maturity structure and funding requirements of local governments, how can we anticipate the trade-off between expected cost and risks in the future? (3) How can we find the correct issuance strategies under risk constraints to fulfil the goal of minimizing debt cost?

\section{Methodology}

\subsection{Notation}

As outlined in Sect. 4, we use the Cox-Ingersoll-Ross (CIR) process to model the evolution scenarios of stochastic interest rate for future bond yields. Based on these scenarios, the stochastic programming model can be formulated to explore the optimal issuance strategy associated with various specific requirements for local governments. For clarity, we outline here the main notations used in our optimization model. The generation of the stochastic interest rate is discussed separately in Sect. 4.

\subsection{Parameters and index sets}

$H$ : length of local government debt planning horizon.

$t_{h}$ : Decision stage in debt planning horizon at which issuance strategies are taken, $h=1, \ldots, H$

$\mathbb{T}:$ Set of decision stages, $\mathbb{T}=\left\{t_{1}, t_{2}, \ldots, t_{H}\right\}$

$k_{m}$ : Maturity of bond $m, m=1,2, \ldots, M$

$\mathbb{K}$ : Set of maturities for local government bond to be issued, $k_{m} \in \mathbb{K}$

$n$ : Scenario index, $n=1,2, \ldots, N$

$\mathbb{N}$ : Set of interest rate scenarios, $n \in \mathbb{N}$

$\psi$ : Upper bound for conditional payment-at-risk $(C P a R)$.

$\rho$ : Upper bound for conditional value-at-risk $(C V a R)$.

$\delta$ : Extended liquidity planning horizon.

$p_{n}$ : Probability associated with scenario $n$

$Q_{t_{h}}^{k_{m}}$ : Number of bonds $m$ with maturity $k_{m}$ to be issued at decision stage $t_{h}$ 
$g_{t_{j}}^{k_{m}}:$ Discount rate for bond $m$ with maturity $k_{m}$ at decision stage $t_{j}$

\subsection{Stochastic variables}

$r_{t_{h}, n}^{k_{m}}$ : Average interest rate of bond $m$ with maturity $k_{m}$ at $t_{h}$, under scenario $n$

$d_{t_{h}, n}^{k_{m}}$ : Cost of bond $m$ with maturity $k_{m}$ that matures after $H$, under scenario $n$

$\mathrm{Pay}_{t_{h}, n}^{k_{m}}$ : Repayments of bond $m$ with maturity $k_{m}$ in units at face value at $t_{h}$ under scenario $n$, which includes the repayments of all bonds $m$ issued before $t_{h}$.

$C_{n}$ : Total cost associated with the issuance strategy under scenario $n$

$P_{t_{h}, n}$ : The total payments of bond issued at $t_{h}$ under scenario $n$. Decision variables are defined for each decision stage as follows.

\subsection{Decision variables}

$x_{t_{h}}^{k_{m}}$ : The proportion of bonds $m$ with maturity $k_{m}$ to be issued at $t_{h}$ associated with the issuance strategy; $\sum_{k \in \mathbb{K}} x_{t_{h}}^{k_{m}}=1$

\subsection{Auxiliary variables}

$Q_{t_{h}}$ : Total number of local government bonds to be issued at decision stage $t_{h}$

$O_{n}$ : Cost of bonds expiring before $H$ associated with the issuance strategy under scenario $n$

$D_{n}$ : Cost of bonds expiring after $H$ associated with the issuance strategy under scenario $n$

$\varphi(\bullet)$ : Discount factor, which is used to calculate the present value of bond payments that mature after the end of the planning horizon $H$.

$1_{A\left(t_{h}\right)}^{k_{m}}:$ An indicator function; if the principals of bond $m$ are paid at $t_{h}, 1_{A\left(t_{h}\right)}^{k_{m}}$ equals 1 , and otherwise 0 .

$F_{n}^{H}$ : The average of cash flow payments on the debt planning horizon, under scenario $n$

$F_{n}^{\delta}$ : the average of cash flow payments on the extended liquidity planning horizon after $H$, under scenario $n$

$F_{n}^{H+\delta}$ : the average of total cash flow payments on the liquidity planning horizon under scenario $n$

$L_{n}$ : The loss function associated with the issuance strategy under scenario $n$

$P a R$ : A quantile of the cash flow distribution associated with the given confidence level

$\phi_{n}$ : Excess payments beyond $P a R$ under scenario $n$

$\gamma_{n}$ : Excess loss beyond $\operatorname{VaR}$ under scenario $n$ 


\subsection{Basic concepts}

\subsubsection{Cost of issued bonds}

Suppose that the local government debt planning horizon is $H$ years, and decisionmakers determine the debt issuance strategy at decision stage $t_{h}, h=1,2, \ldots, H$. Given local governments borrowing requirements and the evolution of associated stochastic variables within the debt planning horizon, the cost of issued bonds can be obtained by algebraic transformation (Hahm and Kim 2003). According to their maturity, we divide the issued bonds into two categories when considering their cost under $n \in \mathbb{N}$ scenarios. Naturally, some bonds issued at $t_{h}$ will have expired by $H$, while others will expire after $H$.

We first consider the cost of issued bonds that have expired by $H$, which contains the interest and principal payments of these bonds. Note that $k_{m} \in \mathbb{K}$ is the maturity of bond $m$. This indicates that if bond $m$ expires before $H, t_{H}-t_{h} \geq k_{m}$. Without loss of generality, we suppose that the available coupon bonds are issued at par and coupons are paid annually. Thus, the quantity $O_{n}, n \in \mathbb{N}$, namely the cost of bonds expired before $t_{H}$ associated with the bond portfolio composition within debt planning horizon, can be defined as

$$
O_{n}=\sum_{h=1}^{H} \sum_{k_{m} \in \mathbb{K}} Q_{t_{h}} x_{t_{h}}^{k_{m}}\left(r_{t_{h}, n}^{k_{m}} k_{m}+1\right)
$$

where $Q_{t_{h}}$ is the debt requirement size for the local government at $t_{h}$ and $r_{t_{h}, n}^{k_{m}}$ represents the interest rate of bond $m$ issued at $t_{h}$ under scenario $n$.

Next, we consider the cost of bond $m$ issued at $t_{h}$ and expiring after $H$, which contains the interest payments before $H$ and the present value of future payments (including both interests and principal) after $H$. The bond expires after $H$, namely $t_{H}-t_{h}<k_{m}$, and will produce future liabilities. Therefore, we define the cost of bond $m$ issued at $t_{h}$, namely $d_{t_{h}, n}^{k_{m}}, n \in \mathbb{N}$, as follows:

$$
d_{t_{h}, n}^{k_{m}}=Q_{t_{h}} x_{t_{h}}^{k_{m}} r_{t_{h}, n}^{k_{m}}(H-h)+Q_{t_{h}} x_{t_{h}}^{k_{m}} \sum_{j=H}^{k_{m}+h-H}\left(\frac{r_{t_{h}, n}^{k_{m}}}{\varphi(j)}+\frac{1}{\varphi\left(k_{m}+h-H\right)}\right)
$$

where the discount factor $\varphi(\bullet)$ is given as

$$
\varphi(j)=\prod_{j=H}^{k_{m}+h-H}\left(1+g_{t_{j}}^{k_{m}}\right)
$$


Accordingly, we can obtain $D_{n}, n \in \mathbb{N}$, which is the cost of total bonds maturing after $H$ associated with bond portfolio composition.

$$
D_{n}=\sum_{h=1}^{H} \sum_{k_{m} \in \mathbb{K}} d_{t_{h}, n}^{k_{m}}
$$

Finally, based on Eqs. (1)-(4), we denote by $C_{n}, n \in \mathbb{N}$, the final total cost with respect to the debt planning horizon of the local government, and define it as follows:

$$
C_{n}=O_{n}+D_{n}
$$

\subsubsection{Cash flow of issued bonds}

Now we consider the cash flows with respect to the issued bond portfolio. Traditionally, local governments have focused on the repayment levels of cash flow involved in the debt cost and fiscal budget because an excessive decline in debt repayable funds may induce a liquidity shortage (19.Balibek and Köksalan 2010). Many researchers consider the level of cash flow payment within the debt planning horizon. However, with the accumulation of total debt, local governments have issued many long-term bonds to alleviate the current repayment pressure. However, this also leads to higher repayment pressure and liquidity risk in the future. To effectively manage these future repayments and liquidity risk, we consider the cash flow payment level within a longer period, $H+\delta$. Here, $\delta$ is the extended liquidity planning horizon after the debt planning horizon $H$, and it represents the period of future liquidity risk that the local government hopes to control.

We define $P a y_{t_{h}, n}^{k_{m}}, n \in \mathbb{N}$ as the repayments of bonds $m$ with maturity $k_{m}$ in units at face value at $t_{h}$ under scenarion, which includes the repayments of all bonds $m$ issued before $t_{h}$. For simplicity, we assume that all repayments of interests and principals are paid between two adjacent decision stages. For example, the period $\left(t_{h-1}, t_{h}\right]$ is covered at $t_{h} . P a y_{t_{h}, n}^{k_{m}}, h=1,2, \ldots H+\delta$ can be expressed as

$$
\operatorname{Pay}_{t_{h}, n}^{k_{m}}=\sum_{i=h-k_{m}+1}^{h} Q_{t_{i}}^{k_{m}}\left(r_{t_{i}, n}^{k_{m}}+1_{A\left(t_{h}\right)}^{k_{m}}\right)
$$

where $r_{t_{i}, n}^{k_{m}}, i \in\left[h-k_{m}+1, h\right]$ is the interest rate of bond $m$ with maturity $k_{m}$ at $t_{i}$ under scenario $n$, and $1_{A\left(t_{h}\right)}^{k_{m}}$ is an indicator function defined as in Sect. 3.1.

Therefore, the total payments for all kinds of issued bonds, $P_{t_{h}, n}, n \in \mathbb{N}$, can be given as

$$
P_{t_{h}, n}=\sum_{k \in \mathbb{K}} P a y_{t_{h}, n}^{k_{m}}
$$


where $P_{t_{h}, n}$ denotes the total payments associated with issuance strategies at $t_{h}$ under scenario $n$.

\subsubsection{Objective function}

The bond cost $C$ in the debt planning horizon is a random variable that contains $N$ scenarios, and the probability of scenario $n$ is $p_{n}$. Decision-makers aim to shape a distribution that can obtain the minimum debt cost under various constraints satisfying the local government's financing requirements. A common objective function is adopted as the expected value of bond cost:

$$
\mathbb{E}[C]=\sum_{n \in \mathbb{N}} p_{n} C_{n}
$$

In this paper, we mainly consider the minimum expected bond cost in the debt planning horizon associated with different issuance strategies. However, it is reductive and unrealistic to use only this objective function to analyze the issues involved in local government debt management. Thus, to increase practicality, the necessary risk constraints are introduced in the subsequent sections.

\subsection{Constraints of liquidity and cost deviation}

Local governments face complex circumstances when issuing bonds to satisfy their financing requirements. Similar to the private sector, which pursues maximum returns under some risk constraints (De Medeiros et al. 2005), local governments need to consider different constraints to meet their specific requirements while pursuing the minimum expected debt cost. Otherwise, their modeling will be unrealistic and impractical. In this Section, we consider two constraints associated with cost deviation and liquidity risk.

\subsubsection{Cost deviation constraint}

When local governments issue bonds to meet their various obligations, decisionmakers usually have a deterministic or random debt management target depending on their fiscal status. Based on this target, cost deviation risk reflects the deviation of the corresponding objective function from the given desired target. An interesting measure of cost deviation risk is the $C V a R$, which is treated as a series of linear constraints, and defined in Rockafellar and Uryasev (Rockafellar and Uryasev 2000). The $C V a R$ reflects the mean tail distribution of the loss function associated with different portfolio compositions, which is bounded to control the level of conditional risk tolerated. A similar measure is proposed by Consiglio and Staino (2012) and Date et al. (2011).

We first define the loss function associated with different issuance strategies for each scenario. Commonly, corresponding to the desired target of local government debt management, the loss is defined as the moments (mean, variance, etc.) of the cost 
deviation from a deterministic value or desired target for decision-makers, which can satisfy their specific requirements. The desired target in this paper, defined by Eq. (8), is the expected value of the cost distribution, which is a commonly adopted target. Thus, the loss function can be shown as

$$
L_{n}=C_{n}-\mathbb{E}[C]
$$

where $L_{n}$ is the loss function associated with various issuance strategies under scenario $n$. Borrowing the corresponding formulations from Rockafellar and Uryasev (2000), the $C V a R$ under scenario $n \in \mathbb{N}$ can be given as

$$
\begin{gathered}
V a R+\frac{1}{1-\alpha} \sum_{n \in \mathbb{N}} p_{n} \gamma_{n} \\
\gamma_{n} \geq L_{n}-V a R \\
\gamma_{n} \geq 0
\end{gathered}
$$

The $\operatorname{VaR}$ value is a quantile for the given confidence level $\gamma_{n}$ is an auxiliary variable that represents the deviation between the loss function $L_{n}$ and $V a R$. Note that we use only the positive deviation from $\operatorname{VaR}\left(\gamma_{n} \geq 0\right)$, so the summation in (10) is always positive. Putting a bound $\rho$ on this summation (10) bounds the $V a R$ of the distribution. $C V a R$ serves as a risk measure associated with cost deviation, and by trading off the expected cost against different levels of $C V a R$, decision-makers can choose different issuance strategies to satisfy their funding requirements.

\subsubsection{Liquidity constraint}

Liquidity risk is a critical concern for local governments when issuing bonds, which mainly arises from the lower level of cash reserves of local governments, perhaps due to a decline in tax revenue or the lender's reluctance to renew its loans. Generally, due to the accumulation of local government debt, the level of net revenue that the government can use to cover matured debt is very low. In addition, the market conditions affecting the demand of investors for local government bonds are beyond the control of local governments (Balibek and Köksalan 2010; Bhandari et al. 2017). This means that local governments may not be able to raise the funds they need at a given time by issuing bonds. Therefore, it is essential to control liquidity risk in both current and future stages effectively. Some decision-makers try to reduce the current payment pressure and liquidity risk level by extending the maturities of issued bonds (long-term bonds). This transfers the current debt repayment pressure and liquidity risk to the future. If excessive debt repayments are transferred to the future, the government may incur higher liquidity risk in the future. To enable local governments to control both current and future liquidity risk effectively, both current and future payments must be examined. For this reason, rather than considering liquidity risk control only within the debt planning horizon $H$, we consider liquidity risk across a 
longer management period, $H+\delta$; that is, $\delta$ is the extended liquidity management horizon after $H$. The liquidity risk considered in the extended period $\delta$ can help local governments to control future liquidity risks effectively, especially when large future repayments are accumulated. This overcomes the shortcoming of managing liquidity risk by transferring it to the future when the local government reduces the current payment pressure by issuing long-term bonds.

Following Balibek and Köksalan(2010), $C P a R$, which is an adjustment of $C V a R$ (Shi et al. 2017; Rockafellar and Uryasev 2000), considers the expected highest debt severity level within the debt planning horizon over the entire scenario set $\mathbb{N}$ for a given confidence level $\alpha$. Here, we use adjusted $C P a R$ to control the liquidity risk associated with different issuance strategies. We consider two parts of cash flow payments, namely $F_{n}^{H}$ and $F_{n}^{\delta}$, where $F_{n}^{H}$ is the total payment level within $H$ and $F_{n}^{\delta}$ is the total payment level involved in the extended liquidity planning horizon $\delta$. By limiting $F_{n}^{H}$ and $F_{n}^{\delta}$, the liquidity risk associated with different issuance strategies within $H+\delta$ can be controlled. The adjusted $C P a R$ formulation considers the average debt payment level within the liquidity planning horizon $H+\delta$ with respect to all scenarios for a given confidence level $\alpha$. The detailed formulations for the adjusted $C P a R$ are as follows:

$$
\begin{aligned}
& F_{n}^{H}=\sum_{h=1}^{H} P_{t_{h}, n} \\
& F_{n}^{\delta}=\sum_{h=H+1}^{H+\delta} P_{t_{h}, n} \\
& F_{n}^{H+\delta} \triangleq \frac{1}{H+\delta}\left(F_{n}^{H}+F_{n}^{\delta}\right)=\frac{1}{H+\delta} \sum_{h=1}^{H+\delta} P_{t_{h}, n} \\
& P a R+\frac{1}{1-\alpha} \sum_{n \in \mathbb{N}} p_{n} \varphi_{n} \\
& \varphi_{n} \geq F_{n}^{H+\delta}-\operatorname{PaR} \\
& \varphi_{n} \geq 0
\end{aligned}
$$

where $F_{n}^{H+\delta}$ is the total average cash flow payment within the liquidity planning horizon $H+\delta$. Note that the adjusted $C P a R$ is always positive, as we take only the positive deviations from $\operatorname{PaR}\left(\varphi_{n} \geq 0\right)$. This implies that if we put a boundary, $\psi$, on the adjusted $C P a R$, we will thereby bound the $P a R$ of the total average payment distribution of cash flow. Using the adjusted $C P a R$, local governments can control the liquidity risk associated with different issued bond portfolio strategies by $\psi$ within the liquidity planning horizon $H+\delta$. 


\subsection{Definition of the optimization model}

The multi-period stochastic programming model for the optimal bond issuance strategy is defined as follows:

$$
\min _{x_{t_{h}}^{k_{m}, \boldsymbol{n} \in \mathbb{N}}} \mathbb{E}\left[C_{n}\right]
$$

subject to

$$
\begin{aligned}
& O_{n}=\sum_{h=1}^{H} \sum_{k_{m} \in \mathbb{K}} Q_{t_{h}} x_{t_{h}}^{k_{m}}\left(r_{t_{h}, n}^{k_{m}} k_{m}+1\right) \\
& d_{t_{h}, n}^{k_{m}}=Q_{t_{h}} x_{t_{h}}^{k_{m}} r_{t_{h}, n}^{k_{m}}(H-h)+Q_{t_{h}} x_{t_{h}}^{k_{m}} \sum_{j=H}^{k_{m}+h-H}\left(\frac{r_{t_{h}, n}^{k_{m}}}{\varphi(j)}+\frac{1}{\varphi\left(k_{m}+h-H\right)}\right) \\
& \sum_{k \in \mathbb{K}} x_{t_{h}}^{k_{m}}=1 \\
& \varphi(j)=\prod_{j=H}^{k_{m}+h-H}\left(1+g_{t_{j}}^{k_{m}}\right) \\
& D_{n}=\sum_{h=1}^{H} \sum_{k_{m} \in \mathbb{K}} d_{t_{h}, n}^{k_{m}} \\
& C_{n}=O_{n}+D_{n} \\
& \operatorname{Pay}_{t_{h}, n}^{k_{m}}=\sum_{i=h-k_{m}+1}^{h} Q_{t_{i}}^{k_{m}}\left(r_{t_{i}, n}^{k_{m}}+1_{A\left(t_{h}\right)}^{k_{m}}\right) \\
& P_{t_{h}, n}=\sum_{k \in \mathbb{K}} P a y_{t_{h}, n}^{k_{m}} \\
& F_{n}^{H}=\frac{1}{H} \sum_{h=1}^{H} P_{t_{h}, n} \\
& F_{n}^{\delta}=\frac{1}{\delta} \sum_{h=H}^{H+\delta} P_{t_{h}, n} \\
& F_{n}^{H+\delta} \triangleq \frac{1}{H+\delta}\left(F_{n}^{H}+F_{n}^{\delta}\right)=\frac{1}{H+\delta} \sum_{h=1}^{H+\delta} P_{t_{h}, n} \\
& P a R+\frac{1}{1-\alpha} \sum_{n \in \mathbb{N}} p_{n} \varphi_{n} \leq \psi
\end{aligned}
$$




$$
\begin{gathered}
\varphi_{n} \geq F_{n}^{H+\delta}-\operatorname{PaR} \\
\varphi_{n} \geq 0 \\
\mathbb{E}\left[C_{n}\right]=\sum_{n \in N} p_{n} C_{n} \\
L_{n}=C_{n}-\mathbb{E}[C] \\
\operatorname{VaR}+\frac{1}{1-\alpha} \sum_{n \in \mathbb{N}} p_{n} \gamma_{n} \leq \rho \\
\gamma_{n} \geq L_{n}-\operatorname{VaR} \\
\gamma_{n} \geq 0
\end{gathered}
$$

We schematically illustrate the optimization procedure in Fig. 1. The aim of decision-makers is to minimize the expected cost, as defined in Sect. 3.2.3, over all of the scenarios within the debt planning horizon. The rest of the notation in the above model is outlined in Sect. 3.1. The equations are a combination of those in the preceding Sects. 3.2 and 3.3. They are explained in detail below.

Equation (19) is the objective function, which is the total expected cost for different issuance strategies under all scenarios within debt planning horizon $H$.

Equations (20)-(25) represent the total debt cost, $C_{n}, n \in \mathbb{N}$, which is composed of interest and principal payments before $H$ and the present value of payments after $H$.

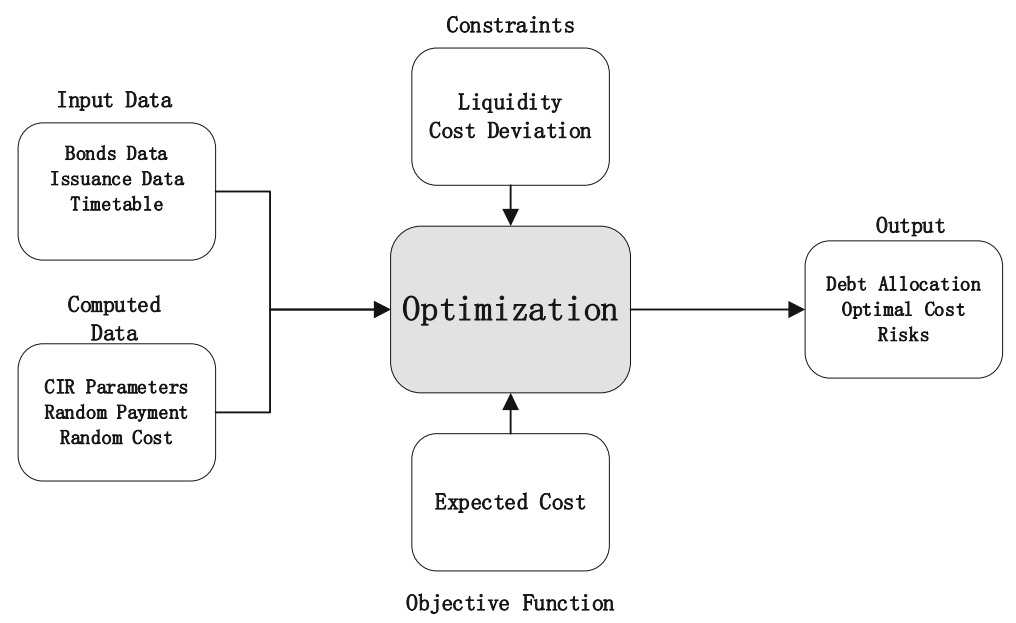

Fig. 1 Optimization procedure 
Equations (26)-(27) provide the cash flow of issuance strategy, $P_{t_{h}, n}, n \in \mathbb{N}$, in each decision stage $t_{h}, h=1,2, \ldots, H+\delta$, under scenario $n$.

Formulas (28)-(33) define the liquidity risk constraint of $C P a R$, which ensures that the average total payment $F_{n}^{H+\delta}$ remains under a specified constant $\psi$ with a given confidence level $\alpha$.

Formulas (34)-(38) represent the cost deviation risk constraint of $C V a R$, which can guarantee that the cost deviation risk does not exceed a specified constant $\rho$ with a given confidence level $\alpha$.

The mechanism of the optimization model discussed above is based on the evolution of the stochastic interest rate in each decision stage. In this paper, we use the CIR process to generate stochastic scenarios for bond yields (Overbeck and Ryden 1997; Kladívko 2007; Glasserman and Kou 2003). We use this approach because some researchers have tested its feasibility and robustness in simulating the evolution of bonds yields (Bhandari et al., 2017). In the next section, we briefly describe the CIR process and the calibration of its parameters.

\section{Monte Carlo generation of interest rate scenarios}

Debt cost is one of the main concerns for local governments when issuing debt, and the interest rates for debt issuance play a key role in calculating debt cost. Unfortunately, we cannot exactly know the future interest rate in advance. Thus, it is necessary to model the evolution of the future interest rate at which the local government bonds to be issued. The future interest rate needs to be modeled as reasonably and realistically as possible. Many term structure models of interest rate can solve this, such as Vasicek (1997) and CIR. In this paper, we assume that the instantaneously compounded short rate follows the CIR process, which has been widely tested by practitioners. Many researchers also demonstrate the robustness of this method in simulating government debt issuance. Next, we offer a simple description of this method in the following Sections.

\subsection{CIR process}

Following the CIR process as described in Glasserman and Kou (2003), the instantaneously compounded short rate $r(t)$ is driven by the following stochastic differential equation:

$$
d r(t)=\beta(\mu-r(t)) d t+\sigma \sqrt{r(t)} d W(t), r(0)=r_{0}
$$

where the parameter vector is $\alpha=(\beta, \mu, \sigma)$ with $\beta, \mu, \sigma$ positive constants. The condition $2 \beta \mu>\sigma^{2}$ ensures that the origin is inaccessible to $r$, and hence that the process $r(t)$ remains positive. $d W(t)$ represents the standard Brownian motion.

The CIR process provides an explicit evolution of bond prices. The process has an affine term structure, so the price of a zero-coupon bond at time $t$ with maturity $T$ can 
be shown to be

$$
P(t, T)=A(t, T) e^{-B(t, T) r(t)}
$$

where $A, B$ are functions of time to maturity $T-t$ and are given by

$$
\begin{gathered}
A(t, T)=\left(\frac{2 h \exp ((\beta+h)(T-t) / 2)}{(\beta+h)(\exp (T-t) h-1)+2 h}\right)^{\frac{2 \beta \mu}{\sigma^{2}}} \\
B(t, T)=\frac{2(\exp (T-t) h-1)}{(\beta+h)(\exp (T-t) h-1)+2 h} \\
h=\sqrt{\beta^{2}+2 \sigma^{2}}
\end{gathered}
$$

By simple algebraic computation, we can arrive at the following yield function

$$
y(t, T)=-\frac{P(t, T)}{T-t}
$$

\subsection{Maximum likelihood estimation (MLE) of parameters}

In this Section, we use historical interest rate data to estimate the parameters of the CIR process. Due to the non-Gaussian distribution of the short rate in the CIR process, we use numerical optimization to obtain the MLE solution.

First, to build the likelihood function, the transfer density function is required. As stated in (Glasserman and Kou 2003), the transition density of $r(t)$ can be shown as

$$
r(t)=\frac{\sigma^{2}\left(1-e^{-\beta(t-u)}\right)}{4 \beta} \chi_{d}^{2}\left(\frac{4 \beta e^{-\beta(t-u)}}{\sigma^{2}\left(1-e^{-\beta(t-u)}\right)} r(u)\right), t>u,
$$

where $d=4 \mu \beta / \sigma^{2}$.

This means that given $r(u), r(t)$ is distributed as $\frac{\sigma^{2}\left(1-e^{-\beta(t-u)}\right)}{4 \beta}$ times a non-central chi-square random variable with $d$ degrees of freedom and a non-centrality parameter:

$$
\lambda=\frac{4 \beta e^{-\beta(t-u)}}{\sigma^{2}\left(1-e^{-\beta(t-u)}\right)} r(u)
$$

From the transition density function, we can get the cumulative distribution function of $r(t)$ as

$$
P(r(t) \leq y \mid r(u))=F_{\chi_{(d, \lambda)}^{2}}\left(\frac{4 \beta y}{\sigma^{2}\left(1-e^{-\beta(t-u)}\right)}\right)
$$


Next, the probability density function can be written as follows:

$$
P_{r(t)}(y \mid r(u))=c p_{\chi_{(d, \lambda)}^{2}}(c y),
$$

where $p_{\chi_{(d, \lambda)}^{2}}(c y)$ is the density of the non-central chi-square distribution and

$$
c=\frac{4 \beta}{\sigma_{2}\left(1-e^{-\beta(t-u)}\right)}
$$

Based on the above, we can obtain the likelihood and log-likelihood functions as follows:

$$
\begin{gathered}
L(\mu, \beta, \sigma ; y)=\prod_{i=2}^{n} c p_{\chi_{(d, \lambda)}^{2}}\left(c y_{i} \mid y_{i-1}\right) \\
l(\mu, \beta, \sigma ; y)=\sum_{i=2}^{n} \log (c)+\sum_{i=2}^{n} \log \left(p_{\chi_{(d, \lambda)}^{2}}\left(c y_{i} \mid y_{i-1}\right)\right),
\end{gathered}
$$

where $y=r_{1}, r_{2}, \cdots, r_{n}$.

Finally, the log-likelihood function is used to calculate the parameter vector $\alpha=$ $(\beta, \mu, \sigma)$ by numerical optimization within the planning horizon.

\section{Empirical analysis}

We apply the optimization model proposed in Sect. 3.4 to local government debt issuance in China. For convenience, we assume that the local government will make an annual issuance plan at the beginning of each year. In line with China's Five-Year Plan (FYP) system, we set the debt planning horizon at 5 years for consistency with the government's budget cycle. The size of the bond to be issued is assumed to be an exogenous variable, which is determined by economic status, fiscal policy, inflation rate, fiscal budget, etc. Following Hahm (2003), to reduce the calculational cost, we also assume that each issuance strategy is time-invariant, which implies that under an issuance strategy the weights of each maturity bond are fixed across the debt planning horizon.

We use the optimization procedure in Sect. 4.2 to calibrate the CIR process with daily data on local government bonds from 2010 to 2015 obtained from a website providing information on Chinese bonds (http://yield.chinabond.com.cn/\#). According to the actual portfolios of bonds issued by local governments, we use data on fixed coupon bonds with maturities of 3 years, 5 years, 7 years, 10 years, 15 years, 20 years, and 30 years over that period to calibrate over 1,728 yields per bond, i.e., a total of 12,096 yields. Without loss of generality, we assume that the numbers of bonds to be issued within the debt planning horizon are 500, 800, 500, 500, and 500, respectively. We also estimate the parameters of the CIR process with MLE method for each bond. The results are listed in Table 1. 
Table 1 Estimated parameters of the CIR process

\begin{tabular}{llll}
\hline Maturity(years) & $\mu$ & $\beta$ & $\sigma$ \\
\hline 3 & 0.48986 & 0.03847 & 0.02632 \\
5 & 0.52468 & 0.03989 & 0.02531 \\
7 & 0.60305 & 0.04075 & 0.02298 \\
10 & 0.78771 & 0.04123 & 0.02145 \\
15 & 0.65340 & 0.04294 & 0.01662 \\
20 & 0.61892 & 0.04496 & 0.01599 \\
30 & 0.63085 & 0.04629 & 0.01531 \\
\hline
\end{tabular}

Now, the estimated parameters in Table 1 are used to generate 3,000 interest rate scenarios, in which each scenario contains 1,250 random yields in 5 years, for a total of 26,250,000 bond yields. Accordingly, we obtain the average yield $r_{t_{h}, n}^{k_{m}}$ of each decision stage to calculate optimal issuance strategy, and we obtain a total of 105,000 bond yields within the debt planning horizon. Based on these bond yields, we analyze the debt cost and risks associated with different compositions of issued bond portfolios to meet local governments' requirements. For any local government, the overall objective of debt management is to minimize the expected cost within the debt planning horizon given the trade-off between the expected cost and risks associated with different issuance strategies to meet funding requirements. Practically, however, local governments have more specific borrowing requirements. For instance, they may fix the cost deviation risk to seek a trade-off between expected cost and liquidity risk. To meet the different specific requirements of local governments, we examine these problems from different perspectives.

For clarity, we first explore the efficient frontier and debt portfolio composition with respect to various issued bond portfolio compositions for local government fiscal requirements in terms of the trade-off between the expected cost and cost deviation risk (see Sect. 5.1). Based on this, we add the liquidity risk constraint to examine the efficient frontier and corresponding debt portfolio composition by the trade-off between the expected bond cost, cost deviation risk and liquidity risk (see Sect. 5.2). Finally, we compare the expected cost and risks with those of the actual borrowing strategies of local governments in China (see Sect. 5.3).

\subsection{The debt allocation with single CVaRConstraint}

The cost deviation risk is associated with the desired target of local government bond issuance, which reflects the deviation of the issuance strategy from the corresponding desired target. To clearly show the relationship between debt cost and cost deviation risk, we illustrate the optimal issuance strategies with the single cost deviation risk $(C V a R)$ constraint in Fig. 2. Figure 2-a displays the efficient frontier to minimize the expected cost with the single $C V a R$ constraint. This result reflects the tradeoff between the expected debt cost and preferences of local governments for different 

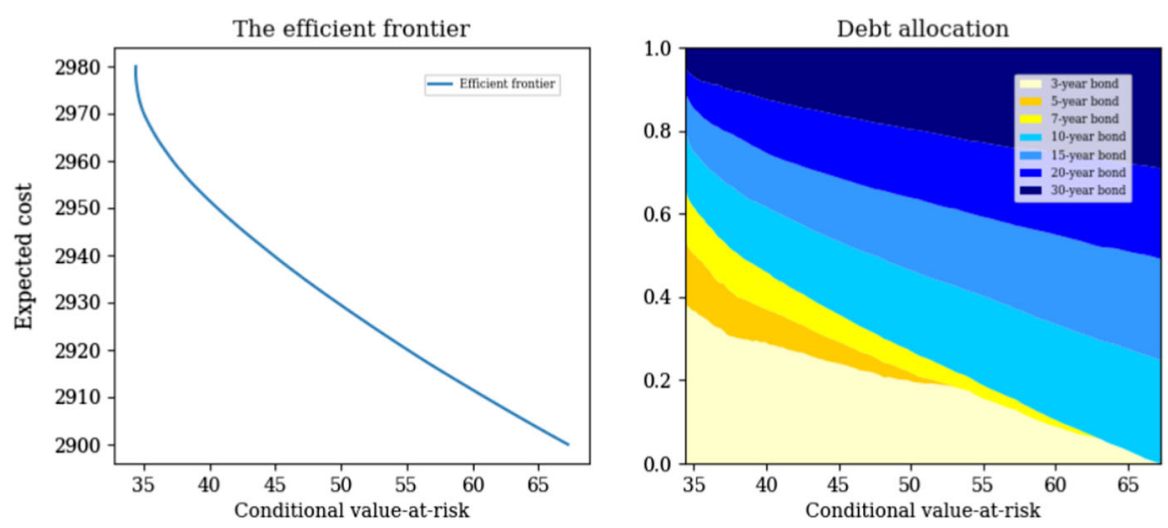

Fig. 2 The efficient frontier a and portfolio compositions with single $C V a R$ constraintb

issuance strategies. As shown in Fig. 2-a, the frontier with a convex shape is a decreasing function of $C V a R$. From a financial point of view, the expected cost of a debt portfolio of fixed-coupon bonds can be reduced by issuing more bonds that will expire after the debt planning horizon $H$. In this case, long-term bonds only need to repay some of the coupons paid before the debt planning horizon; as mentioned in Sect. 3.2, the remaining coupons and principals are considered with the present value. In particular, compared with the paid coupons in each decision stages, principals account for a larger proportion of debt service costs. Thus, the larger the proportion of long-term bonds issued, the lower the expected cost of the issuance strategies.

Figure $2 \mathrm{~b}$ shows the debt portfolio composition structure with respect to different values of $C V a R$. As shown in Fig. 2b, when $C V a R$ shifts from low to high, the portfolio composition of various issued bonds with different maturities increasingly displays long-term bonds that expire after the debt planning horizon. At the same time, the larger the proportion of long-term bonds that expire after the debt planning horizon, the lower the expected cost. This relationship is demonstrated by the decreasing curve of the efficient frontier in Fig. 2a. We also find that the lower the level of $C V a R$, the larger the proportion of short-term bonds, and the higher the corresponding debt cost. Some short-term bonds have expired by the end of the debt planning horizon, and the principals of all bonds whose maturities do not exceed the debt planning horizon must be repaid. For example, given a 5-year debt planning horizon, a 3-year bond issued in each year will repay the principals three times. However, a 10-year bond will not repay any principals within a 5-year debt planning horizon.

\subsection{Debt allocation with both CPaRand CVaRconstraints}

Liquidity risk plays a critical role in local governments' debt management. Higher cash flow payments may increase the uncertainty of local governments' fiscal budgets and trigger a liquidity shortage. In Sect. 5.1, we explore the optimal portfolio composition with a $C V a R$ constraint only. To improve the practicality of the model, we now consider both cost deviation risk $(C V a R)$ and liquidity risk $(C P a R)$ constraints to 
minimize the expected cost associated with various issuance strategies. Specifically, to meet the actual requirements of local government debt management, we analyze three optimal bond issuance cases. These three cases correspond to the three actual requirements of local government debt management in issuing bonds, as follows: (1) a trade-off between liquidity risk $(C P a R)$ and expected bond cost under a given cost deviation risk $(C V a R)$; (2) a trade-off between cost deviation risk and expected cost under a given liquidity risk; and (3) a trade-off between expected cost, liquidity risk, and cost deviation risk.

Due to their accumulation of debt, local governments in China usually issue longterm bonds to reduce their current debt repayment pressure. To control the future liquidity risk caused by the issuance of a large number of long-term bonds, we consider a $\delta$-year period in advance to control the future payment levels of cash flow after the debt planning horizon. Here, we set the extended liquidity planning horizon $\delta$ as 5 years, for the following reasons. (1) Five years are consistent with the period of China's FYP. (2) As the debt planning horizon is also 5 years, we consider the repayments of next debt planning horizon in advance to prepare for bond issuance over the next horizon. The maturities of some of the bonds issued within the debt planning horizon exceed 10 years. Therefore, only some of the total interest payments within the liquidity planning horizon $(H+\delta=10$ years) for these bonds are considered. Based on this, the more bonds with maturities exceeding 10 years are issued, the lower the interest and principals paid within the period $H+\delta$. This is also consistent with local governments' actual issuance strategy of reducing payment pressure within period $H$ by issuing long-term bonds whose maturities exceed $H+\delta$ years.

\subsubsection{Case for two constraints with different $C V a R$ and fixed $C P a R$}

We examine the trade-off between the expected cost and cost deviation risk associated with different issuance strategies under a fixed liquidity risk constraint. For convenience, we set $C P a R=220$ and give the efficient frontier and issued bond portfolio composition in Fig. 3. As shown in Fig. 3a, the efficient frontier with a convex shape
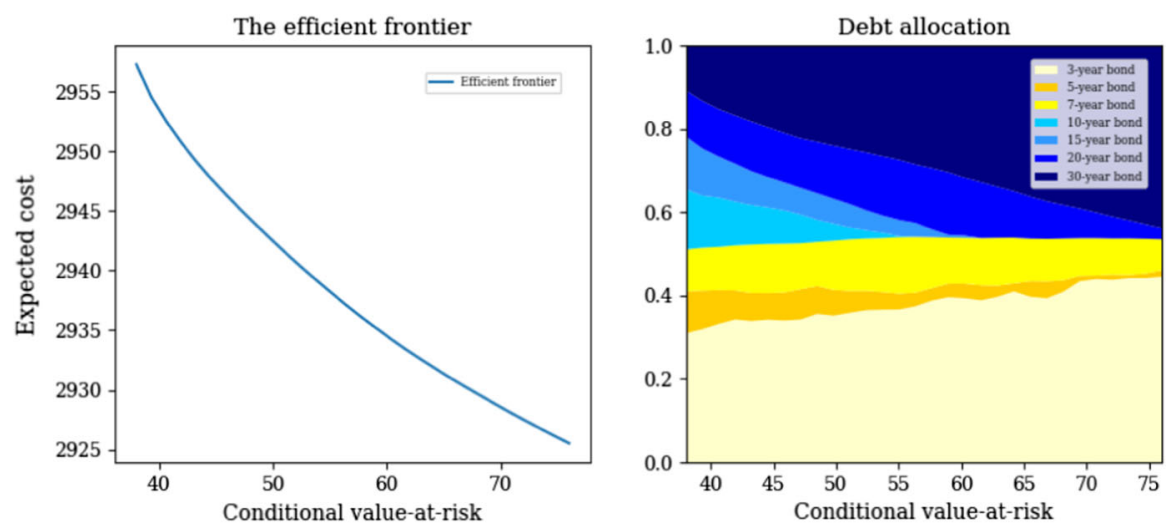

Fig. 3 The efficient frontier (Fig. 3a) and debt composition with $C P a R=220$ and different $C \operatorname{VaR}$ (Fig. 3-b) 
is a decreasing function of $C V a R$ under a fixed $C P a R$ constraint. With an increase in $C V a R$ level, the expected debt cost within the debt planning horizon ( $H=5$ years) gradually decreases. From a financial point of view, the reduced expected cost of issuance strategies within a debt planning horizon can be achieved by issuing longterm bonds. Long-term bonds only need to repay some of the coupons paid before the debt planning horizon, while, as mentioned in Sect. 3.2, the remaining coupon and principals to be accounted for after the debt planning horizon are the present value discounted by a long period. Consequently, the larger the proportion of the long-term bonds issued, the lower the expected cost achieved.

Figure $3 \mathrm{~b}$ shows the issuance portfolio composition of local governments under different $C V a R$ and fixed $C P a R$ constraints. The total proportion of bonds with maturities within 10 years, including 3-year, 5-year, and 7-year bonds, is relatively stable, as all of the issued portfolio compositions in Fig. 3 are obtained under the constraint of fixed $C P a R$. As is well known, in the liquidity planning horizon $(H+\delta=$ 10 years), the principals of bonds with maturities within 10 years, such as 3 -year, 5-year, and 7-year bonds, need to be repaid many more times than do bonds that mature after 10 years. Meanwhile, as a bond's interest payments are equal to only a small proportion of its principals, $C P a R$, which represents the average payment level, is mainly determined by the total payments of principals associated with bonds that mature within the liquidity planning horizon. Therefore, under a fixed $C P a R$ level, we clearly find in Fig. $3 b$ that the total proportion of bonds that mature within the liquidity planning horizon, including 3-year, 5-year, and 7-year bonds, is relatively stable. This reflects the specific liquidity risk constraint presented by a fixed $C P a R$ level for local government bond issuance. This also means that the liquidity risk presented by $C P a R$ is mainly affected by bonds that mature within the liquidity planning horizon.

Regarding the rest of the issued bonds, including those with 10-year, 15-year, 20year, and 30-year maturities, the more of these bonds are issued, the lower the expected cost. For these bonds, the only costs to be accounted for are the interest payments within the debt planning horizon, because the principals will be repaid long after the end of the horizon. However, due to the relative stability of the total proportions of the 3-year, 5-year, and 7-year bonds, the total proportions of the 10-year, 15-year, 20-year, and 30 -year bonds also change slightly. As the 30 -year bond has the longest maturity, this type of bond makes a greater contribution to cost reduction than do other bonds that mature after the debt planning horizon. Thus, for the optimal debt management goal associated with the minimization of expected cost, the proportion of 30-year bonds sharply increases as $C V a R$ shifts from low to high. This is illustrated in Fig. 3b. Accordingly, the expected cost decreases clearly.

In short, for a given constraint of fixed liquidity risk, with the allocation conversion of the proportion of bonds that mature after $H$, different levels of the expected cost associated with the debt planning horizon can be achieved. For example, as shown in Fig. 3-b, under a fixed level of $C P a R$ (which is mainly affected by bonds that mature after $H+\delta$ ), based on the decision-maker's preference for issuance strategies, it may issue a smaller proportion of bonds with the longest maturities. In contrast, when decision-makers aim to minimize the expected cost, a larger proportion of bonds with the longest maturity will be issued. However, this strategy deviates from the 
Table 2 Results for the case of two constraints with different $C V a R$ and fixed $C P a R$

\begin{tabular}{lllllllll}
\hline 3 Year & 5 Year & 7 Year & 10 Year & 15 Year & 20 Year & 30 Year & $\begin{array}{l}\text { Expected } \\
\text { Cost }\end{array}$ & CVaR \\
\hline 0.3093 & 0.1006 & 0.1005 & 0.1447 & 0.1263 & 0.1104 & 0.1082 & 2957.3091 & 38 \\
0.3189 & 0.0925 & 0.1033 & 0.1250 & 0.1133 & 0.1138 & 0.1331 & 2954.5561 & 39.3103 \\
0.332 & 0.0808 & 0.1040 & 0.1182 & 0.0985 & 0.1135 & 0.1530 & 2952.5305 & 40.6207 \\
0.3424 & 0.0697 & 0.1083 & 0.1047 & 0.0911 & 0.1156 & 0.1682 & 2950.7586 & 41.9311 \\
0.3388 & 0.0671 & 0.1162 & 0.0951 & 0.0812 & 0.1190 & 0.1825 & 2949.1783 & 43.2414 \\
0.3420 & 0.0636 & 0.1180 & 0.0876 & 0.0730 & 0.1192 & 0.1966 & 2947.7208 & 44.5517 \\
0.3400 & 0.0671 & 0.1172 & 0.0799 & 0.0670 & 0.1184 & 0.2104 & 2946.3753 & 45.8621 \\
0.3424 & 0.0725 & 0.1104 & 0.0689 & 0.0641 & 0.1188 & 0.2228 & 2945.1026 & 47.1724 \\
0.3558 & 0.0667 & 0.1062 & 0.0528 & 0.0639 & 0.1232 & 0.2313 & 2943.8721 & 48.4823 \\
0.3516 & 0.0615 & 0.1184 & 0.0408 & 0.0598 & 0.1274 & 0.2405 & 2942.6656 & 49.7931 \\
0.3586 & 0.0522 & 0.1239 & 0.0283 & 0.0564 & 0.1319 & 0.2487 & 2941.4898 & 51.1034 \\
0.3648 & 0.0465 & 0.1253 & 0.0199 & 0.0479 & 0.1387 & 0.2570 & 2940.3597 & 52.4137 \\
0.3659 & 0.0422 & 0.1298 & 0.0127 & 0.0411 & 0.1423 & 0.2660 & 2939.2674 & 53.7241 \\
0.3663 & 0.0380 & 0.1358 & 0.0025 & 0.0387 & 0.1443 & 0.2745 & 2938.2115 & 55.0345 \\
0.3742 & 0.0326 & 0.1339 & 0 & 0.0333 & 0.1404 & 0.2857 & 2937.1766 & 56.3448 \\
0.3878 & 0.0299 & 0.1223 & 0 & 0.0186 & 0.1468 & 0.2946 & 2936.1852 & 57.6552 \\
0.3957 & 0.0326 & 0.1106 & 0 & 0.0069 & 0.1498 & 0.3044 & 2935.2425 & 58.9655 \\
0.3933 & 0.0351 & 0.1099 & 0 & 0.0056 & 0.1386 & 0.3175 & 2934.3215 & 60.2758 \\
0.3883 & 0.0362 & 0.1132 & 0 & 0 & 0.1339 & 0.3284 & 2933.4428 & 61.5862 \\
0.3967 & 0.0269 & 0.1148 & 0 & 0 & 0.1224 & 0.3392 & 2932.6146 & 62.8966 \\
0.4096 & 0.0192 & 0.1099 & 0 & 0 & 0.1115 & 0.3498 & 2931.8142 & 64.2069 \\
0.3968 & 0.0377 & 0.1018 & 0 & 0 & 0.1008 & 0.3630 & 2931.0364 & 65.5172 \\
0.3932 & 0.0406 & 0.1018 & 0 & 0 & 0.0905 & 0.3739 & 2930.2907 & 66.8276 \\
0.4087 & 0.0276 & 0.1002 & 0 & 0 & 0.0807 & 0.3828 & 2929.5646 & 68.1379 \\
\hline & & & & & & & &
\end{tabular}

preferences of decision-makers to some extent. Under a fixed $C P a R$ level, decisionmakers can choose sound issuance strategies according to their different preferences and the requirements of expected cost within the debt planning horizon. More detailed numerical computational results can be found in Table 2.

\subsubsection{Case of two constraints with different CPaR and fixed CVaR}

We explore the trade-off between expected cost and liquidity risk associated with different issuance strategies under a fixed cost deviation risk measured by $C V a R$. For convenience, we set $C V a R=50$ and give the efficient frontier and issued bond portfolio compositions in Fig. 4. As shown in Fig. 4-a, the efficient frontier is an increasing function of $C P a R$ under a fixed level of $C V a R$. As mentioned in Sect. 3.3.2, $C P a R$ represents the mean tail distribution of average total payments exceeding $P a R$ with confidence level $\alpha$ within the liquidity planning horizon $H+\delta$. As $C P a R$ shifts from 

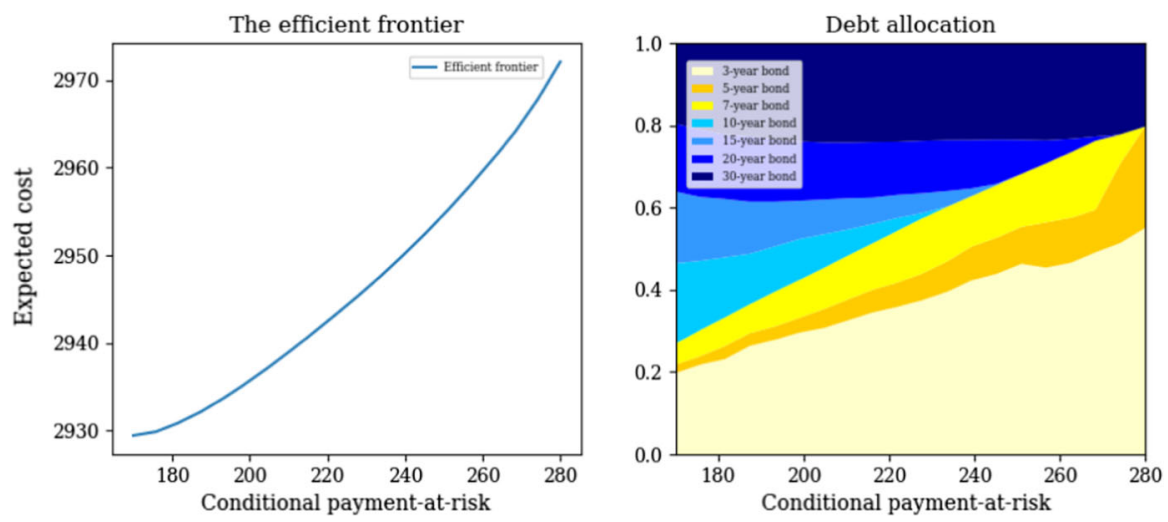

Fig. 4 The efficient frontiera and portfolio composition with $C V a R=50$ and different $C P a R$

low to high, the expected debt cost within the debt planning horizon ( $H=5$ years) increases gradually. Practically, from a financial point of view, the expected cost for the issuance strategies within the debt planning horizon can be increased by issuing short-term bonds that mature before $H$. This is because short-term bonds need to repay their principals many times within the debt planning horizon, and the principals account for a large part of the expected cost. Consequently, the larger the proportion of short-term bonds issued, the higher the expected cost achieved.

Figure 4-b shows the portfolio compositions of local government bonds issued under different $C P a R$ and fixed $C V a R$ constraints. We see that the proportion of 30year bonds is relatively stable because these bonds play the greatest role in changes in $C V a R$. Thus, when $C V a R$ is fixed in Fig. 4, the proportion of issued 30-year bonds changes only slightly. In Fig. 4-b, which shows the optimal issuance portfolio composition under a fixed $C V a R$, with a shift in $C P a R$ from low to high, we can clearly see the allocation conversion of the total proportions of bonds that mature before $H+\delta$ (including 3-year, 5-year, and 7-year bonds) and bonds that mature after $H+\delta$ (including 10-year, 15-year, 20-year, and 30-year bonds).

As is well known, within the liquidity planning horizon $(H+\delta=10$ years $)$, the principals of bonds with maturities within 10 years, such as 3-year, 5-year, and 7-year bonds, need to be repaid many more times than those of bonds maturing after 10 years. Meanwhile, as the bond's interest payments equal only a small proportion of its principals, the $C P a R$ that represents the average payment level is mainly determined by the total payments of principals associated with those bonds matured within the liquidity planning horizon. As $C P a R$ levels are mainly affected by the repaid principal levels, the more bonds are issued (including 3-year, 5-year, and 7-year bonds) that mature before $H+\delta$, the higher the payment levels achieved. Similarly, the more bonds are issued (including 10-year, 15-year, 20-year, and 30-year bonds) that mature after $H+\delta$, the lower the payment levels achieved. As shown in Fig. 4-b, when the $C P a R$ level is relatively low, such as $C P a R=180$, the smaller the total proportion of these bonds that mature before $H+\delta$ (including 3-year, 5-year, and 7-year bonds) and the larger total proportion of these bonds that mature after $H+\delta$ (including 10-year, 15-year, 
20-year, and 30-year bonds) issued. Conversely, when the $C P a R$ level is higher, the higher the total proportion of these bonds that mature before $H+\delta$ (including 3-year, 5 -year, and 7-year bonds) and the lower the total proportion of these bonds that mature after $H+\delta$ (including 10-year, 15-year, 20-year, and 30-year bonds) issued.

In short, with the allocation conversion of the total proportions of these two types of bonds (i.e., maturing before and after $H+\delta$, respectively), different levels of repayment within the liquidity planning horizon can be achieved. For example, as shown in Fig. 4b, when decision-makers face higher current repayment pressure, they will issue more long-term bonds that mature after $H+\delta$ to alleviate the current repayment pressure, and when decision-makers face a higher repayment pressure in the future stage, they will issue more short-term bonds that mature before $H+\delta$ to alleviate the future repayment pressure. According to the different fiscal budget statuses, under a fixed $C V a R$ level, decision-makers can choose sound $C P a R$ levels associated with its realistic issuance requirements within the liquidity planning horizon. More detailed numerical computational results can be found in Table 3.

Table 3 Results for the case of two constraints with different $C P a R$ and Fixed $C V a R$

\begin{tabular}{|c|c|c|c|c|c|c|c|c|}
\hline 3 Year & 5 Year & 7 Year & 10 Year & 15 Year & 20 Year & 30 Year & $\begin{array}{l}\text { Expected } \\
\text { Cost }\end{array}$ & $C P a R$ \\
\hline 0.1972 & 0.0206 & 0.0511 & 0.1954 & 0.1746 & 0.1650 & 0.1961 & 2929.4551 & 170 \\
\hline 0.2178 & 0.0203 & 0.0638 & 0.1685 & 0.1553 & 0.1636 & 0.2107 & 2929.8821 & 175.7895 \\
\hline 0.2310 & 0.0316 & 0.0700 & 0.1461 & 0.1423 & 0.1567 & 0.2223 & 2930.8905 & 181.5789 \\
\hline 0.2630 & 0.0314 & 0.0701 & 0.1230 & 0.1268 & 0.1583 & 0.2275 & 2932.1483 & 187.3684 \\
\hline 0.2778 & 0.0326 & 0.0838 & 0.1105 & 0.1095 & 0.1523 & 0.2335 & 2933.6913 & 193.1579 \\
\hline 0.2956 & 0.0356 & 0.0921 & 0.0995 & 0.0937 & 0.1447 & 0.2388 & 2935.3825 & 198.9474 \\
\hline 0.3071 & 0.0458 & 0.1003 & 0.0816 & 0.0849 & 0.1387 & 0.2416 & 2937.2012 & 204.7368 \\
\hline 0.3259 & 0.0506 & 0.1071 & 0.0629 & 0.0760 & 0.1357 & 0.2416 & 2939.1402 & 210.5263 \\
\hline 0.3451 & 0.0551 & 0.1134 & 0.0465 & 0.0640 & 0.1354 & 0.2404 & 2941.1578 & 216.3158 \\
\hline 0.3586 & 0.0589 & 0.1262 & 0.0311 & 0.0561 & 0.1290 & 0.2401 & 2943.2373 & 222.1053 \\
\hline 0.3746 & 0.0651 & 0.1342 & 0.0131 & 0.0478 & 0.1278 & 0.2376 & 2945.3712 & 227.8947 \\
\hline 0.3951 & 0.0743 & 0.1331 & 0 & 0.0377 & 0.1240 & 0.2359 & 2947.6089 & 233.6842 \\
\hline 0.4228 & 0.0825 & 0.1228 & 0 & 0.0185 & 0.1178 & 0.2356 & 2950.0015 & 239.4736 \\
\hline 0.4388 & 0.0875 & 0.1282 & 0 & 0.0030 & 0.1079 & 0.2345 & 2952.5119 & 245.2632 \\
\hline 0.4631 & 0.0896 & 0.1289 & 0 & 0 & 0.0833 & 0.2352 & 2955.1725 & 251.0526 \\
\hline 0.4539 & 0.1095 & 0.1435 & 0 & 0 & 0.0566 & 0.2365 & 2957.9926 & 256.8421 \\
\hline 0.4657 & 0.1094 & 0.1594 & 0 & 0 & 0.0324 & 0.2332 & 2960.9794 & 262.6315 \\
\hline 0.4908 & 0.1037 & 0.1679 & 0 & 0 & 0.0104 & 0.2271 & 2964.1078 & 268.4211 \\
\hline 0.5134 & 0.1931 & 0.0714 & 0 & 0 & 0 & 0.2223 & 2967.7895 & 274.2105 \\
\hline 0.5497 & 0.2471 & 0 & 0 & 0 & 0 & 0.2033 & 2972.0996 & 280 \\
\hline
\end{tabular}




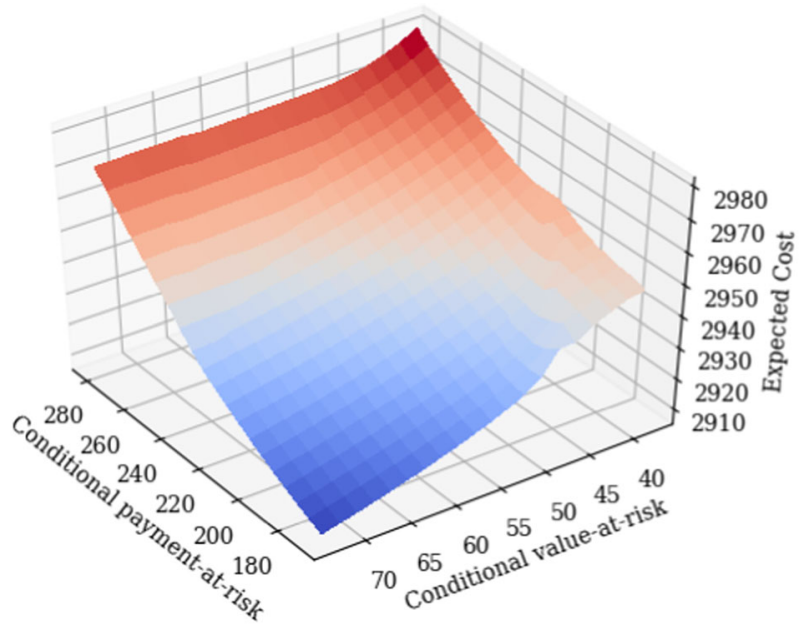

Fig. 5 The efficient frontier with different $C V a R$ and $C P a R$

\subsubsection{Case for two constraints with different $C P a R$ and $C V a R$}

In this Section, we examine the trade-off between expected cost, cost deviation risk, and liquidity risk associated with various issuance strategies. Figure 5 shows the efficient frontier to minimize the expected debt cost with different constraints of $C V a R$ and $C P a R$ with various issuance strategies. We find that the debt cost increases as $C P a R$ increases, and decreases as $C V a R$ increases. This efficient frontier provides a reference criterion for the bond issuance of local governments. Decision-makers can weigh the advantages and disadvantages of actual bond issuance strategies by comparing them with the efficient frontier.

Combining the above discussion with Figs. 3, 4 and 5, we can make the following two clear inferences.

(1) Under a fixed liquidity risk constraint $(C P a R)$, the total proportion of bonds that mature before $H+\delta$ is relatively stable, and decision-makers can select different levels of expected cost by the allocation conversion of proportions of bonds that mature after $H+\delta$, which reflect the preferences of local governments for different issuance strategies.

(2) Under a fixed cost deviation risk constraint $(C V a R)$, the proportion of bonds with the longest maturity is relatively stable, and decision-makers can select different levels of repayment within a liquidity planning horizon by converting the total proportions of these two types of bonds (i.e., maturing before and after $H+\delta$, respectively) to alleviate current or future liquidity risk.

In short, to minimize the expected cost, decision-makers can select sound issuance strategies by considering the liquidity risk and cost deviation risk constraints, which reflect a local government's degree of tolerance of repayment and preference for issuance strategies, respectively. 


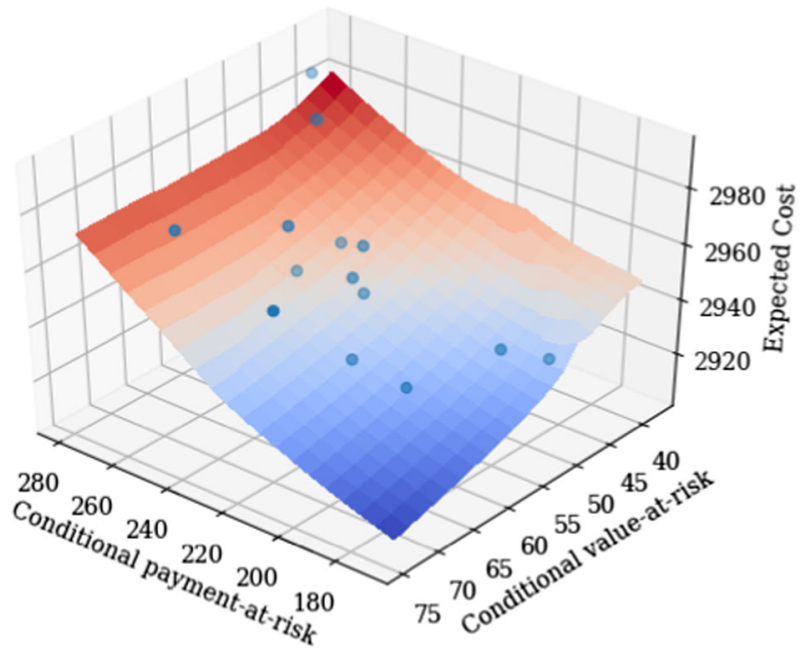

Fig. 6 A comparison of the efficient frontier and actual bond portfolios issued by local governments in China

\subsection{Comparison of the efficient frontier and actually issued bond portfolios}

We obtain the efficient frontier with different requirements for local governments in Sect. 5.2. However, an even more important task is to compare the efficient frontier obtained by solving the proposed model with various bond portfolio compositions actually issued by local governments in China. Under the same scenarios, we derive the efficient frontier associated with different issuance strategies and further compare the efficient frontier with the 15 actual bond portfolios used by local governments to meet funding requirements. In Fig. 6, the corresponding 15 actual bond portfolios, plotted by blue dots, are all located above the efficient frontier associated with the different issuance strategies. This implies that the efficient frontier performs better than the bond portfolios actually issued by local governments in terms of meeting funding requirements, which suggests that local governments can further improve the performance of their issuance strategies by referring to the efficient frontier.

The proposed model in this paper can also be used for debt issuance in other regions. For example, for municipal bonds in Europe and the United States, such bonds could easily be issued to raise funds, but the federal state would not give insurance for these debts. Under the circumstances, to prevent the debt crisis, a solidarity system was gradually formed among EU member states to resist the debt risk. The structure of the solidarity system does provide some protection against debt risk. However, if the debt accumulation to a certain extent, easy to trigger a chain reaction, may lead to a full-blown debt crisis, which is more destructive. This would also force governments to issue long-term bonds to offset short-term debt risk, that is, they transfer the current debt to the future by issuing long-term. It is just a short-term expedient for the present, but it is also a bomb for the future. Therefore, it is necessary to find an effective issuance policy to control future liquidity risk. Especially for some countries in the alliance which have serious debt payment pressure, as constructed by our model, 
they can directly take long-term liquidity risks into account in the bond issuance process and select the optimal bond issuance policy to control long-term liquidity risks. For example, decision-maker can set a upper threshold, such as the ratio of local government debt to GDP, to control long-term liquidity risks. In this case, local government can decide the issuance composition of bonds on the premise of the cash flow of debt repayment in the future, so as to control the long-term liquidity risk level and enhance the sustainability of local government debt.

In general, our approach may not be directly applicable elsewhere because of differences in sovereign debt issuance policies. However, the idea of the model can be used for reference, that is, when making the decision of issuing debt in the current debt period, the debt issuing in the future period should be considered in advance, which is helpful to improve the debt sustainability of the government.

\section{Concluding remarks}

In this paper, we address the problem of local governments' optimal debt issuance in China using a multi-period stochastic programming model. The stochastic scenarios of future interest rate are modeled using the CIR process based on MLE calibration. The optimal criterion is the $C P a R$ within the liquidity planning horizon and the $C V a R$ of the losses associated with the expected cost of the issuance strategy. We first explore the efficient frontier by minimizing the expected cost under different $C P a R$ and $C V a R$ constraints. We also compare the performance of the efficient frontier and the actual issuance strategies of local governments in China. The efficient frontier performs well under the same stochastic scenarios.

The main contributions of this paper are as follows:

(1) To effectively control both the current and future liquidity risks associated with bond issuance for local governments, we use a longer liquidity planning horizon $H+\delta$ than the current debt planning horizon $H$ to manage both current and future liquidity risk.

(2) By analyzing the empirical results, we find that under a fixed constraint of liquidity risk $(C P a R)$, decision-makers can select different levels of expected cost by converting each proportion of those bonds matured after $H+\delta$. In addition, under a fixed constraint of cost deviation risk $(C V a R)$, decision-makers can select different repayment levels by converting the total proportions of those two types of bonds (i.e., maturing before or after $H+\delta$ ) to alleviate current or future liquidity riks.

(3) We use the multi-period stochastic programming model to address the problem of local government bond issuance, and we further analyze the efficient frontiers and bond portfolio compositions under different risk constraints. Finally, we empirically compare the efficient frontier with actual issuance strategies issued by Chinese local governments and demonstrate the superiority of our model.

This research can be extended in many directions. For example, when a local government faces considerable debt maturity, it may use the strategy of debt replacement to extend its debt maturity and even reduce debt cost. In future research, we will explore 
the combination of issuance strategy with a debt replacement strategy. We may also consider other uncertainty factors, such as the inflation rate, to further analyze the practicality of bond issuance strategies, as the inflation rate has a significant impact on the cost of financing local government debt in the long run.

Funding This research is supported by the National Natural Science Foundation of China (No. 71761029), Natural Science Foundation of Inner Mongolia Autonomous Region (No. 2017MS717), Program for Innovative Research Team in Universities of Inner Mongolia Autonomous Region (No. NMGIT1405).

\section{Declarations}

Conflicts of interest The authors have no conflicts of interest to declare that are relevant to the content of this article.

\section{References}

Adamo M, Amadori AL, Bernaschi M, Chioma CL, Marigo A, Piccoli B, Iacovoni D (2004) Optimal strategies for the issuances of sovereign debt securities. Int J Theor Appl Finance 7:805-822

Balibek E, Köksalan M (2010) A multi-objective multi-period stochastic programming model for sovereign debt management. Eur J Oper Res 205:205-217

Bhandari A, Evans D,Golosov M, Sargent T (2017) The optimal maturity of government debt. Working Paper

Bolder DJ (2003) A stochastic simulation framework for the government of Canada's debt strategy. Available at SSRN 1082792

Consiglio A, Staino A (2012) A stochastic programming model for the optimal issuance of government bonds. Ann Oper Res 193:159-172

Consiglio A, Zenios SA (2015) Risk management optimization for sovereign debt restructuring. J Global Devel 6:181-213

Date P, Canepa A, Abdel-Jawad M (2011) A mixed-integer linear programming model for optimal sovereign debt issuance. Eur J Oper Res 214:749-758

Draksaite A, Snieska V, Valodkiene G et al (2015) Selection of government debt evaluation methods based on the concept of sustainability of the debt. Procedia Soc Behav Sci 213:474-480

Eisl A, Ochs C, Pichler S (2016) Sovereign debt issuance under fiscal budget uncertainty and market frictions. In: 29th Australasian finance and banking conference

Fang L, Chai J (2017) the optimal size and risk control of the local government to issue bonds: based on the comparison of four provinces in China. J Centr Univ Finance Econ 000(010):12-20

Faraglia E, Marcet A, Oikonomou R, Scott A (2019) Government debt management: the long and the short of it. Rev Econ Stud 86:2554-2604

Ferrari G (2018) On the optimal management of public debt: a singular stochastic control problem. SIAM J Control Optim 56:2036-2073

Ferrarini B, Arief R, Raghbendra J (2012) Public debt sustainability in developing Asia. Routledge, London

Glasserman P, Kou SG (2003) The term structure of simple forward rates with jump risk. Math Finance: Int J Math Stat Financial Econ 13(3):383-410

Hahm JH, Kim J (2003) Cost-at-risk and benchmark government debt portfolio in Korea. Int Econ J 17:79-103

Hu X, Lei L, Kou X (2020) Determinations on the maturity of China's local government bonds: from the perspective of investor's asymmetric information. Syst Eng 38:122-132

Kladívko K (2007) Maximum likelihood estimation of the Cox-Ingersoll-Ross process: the Matlab implementation. Tech Comput Prag, 7(8)

Markowitz H (1952) Portfolio selection. J Finance 7:77-91

De Medeiros OL, Cabral RSV, Baghdassarian W, de Almeida MA (2005) Sovereign debt strategic planning and benchmark composition 
Missale A (2000) Optimal debt management with a stability and growth pact. Available at SSRN 627343

Overbeck L, Ryden T (1997) Estimation in the cox-Ingersoll-ross model. Economet Theor 13:430-461

Proite A (2015) Texto para discussão n. 18: sovereign debt risk modeling and portfolio management

Rockafellar RT, Uryasev S (2000) Optimization of conditional value-at-risk. J Risk 2:21-42

Shi J, Wang Y, Fu R, Zhang J (2017) Operating strategy for local-area energy systems integration considering uncertainty of supply-side and demand-side under conditional value-at-risk assessment. Sustainability 9:1655

Shi X, Wang H, Fu L (2020) Theoretical model and empirical study on the dual-track issuance structure of local government bonds. Finance Tax Res 1:41-55

Sun L (2019) The structure and sustainability of China's debt. Camb J Econ 43:695-715

Tang J, Tong M, Liu N (2020) Analysis of liquidity measurement and influencing factors of local government bond market in China. Stat Decis 17:143-147

Vasicek O (1997) An equilibrium characterization of the term structure. J Finance Econ 5(2):177-188

Wang X, Fan Q (2012) Research on the early-warning system of risks in local government debt. J Comput 7(4):851-857

Yin Q, Chen Z (2018) Study on the optimal allocation of issuance amount of local government debt in China. Chin J Manag Sci 026(001):90-97

Zenios SA, Consiglio A, Athanasopoulou M, Moshammer E, Gavilan A, Erce A (2019) Risk management for sovereign debt financing with sustainability conditions. Global Monetary Policy Inst Work Paper doi:https://doi.org/10.24149/gwp367

Publisher's Note Springer Nature remains neutral with regard to jurisdictional claims in published maps and institutional affiliations. 